\title{
Risk factors of hospital-acquired malnutrition in children: A study in a rural hospital of West Borneo, Indonesia
}

\author{
Damar Prasetya ${ }^{1^{*}}$, Sri Haryanti ${ }^{2} \&$ Neti Nurani ${ }^{1}$ \\ ${ }^{1}$ Department of Child Health, Faculty of Medicine, Nursing and Public Health, \\ Universitas Gadjah Mada \& Dr. Sardjito General Hospital, Yogyakarta, Indonesia; \\ ${ }^{2}$ Parindu Hospital, Sanggau Regency, West Borneo Province, Indonesia.
}

\begin{abstract}
Introduction: Hospital-acquired malnutrition (HAM) is prevalent among hospitalised children in developing countries. This condition relates to worse clinical outcomes, prolongs length of stay in hospitals, and increases mortality. A multidisciplinary approach should be performed to prevent and manage this problem. However, HAM is often underdiagnosed, especially in rural hospitals with limited human resources. This study aims to delineate the risk factors of HAM among hospitalised children in a rural hospital. Methods: This nested case-control study derived from the implementation of a nutritional screening programme in Parindu Hospital, Sanggau, West Borneo, was conducted from December 2018 to February 2019. HAM was defined as a loss of body weight of $>2 \%$ after hospitalisation. Independent variables such as the age of patients, fever, gastrointestinal loss, pre-existing malnutrition, length of stay, and grade of disease were analysed in univariate and multivariate analyses using logistic regression. Risk factors were expressed as odds ratio and adjusted odds ratio ( $a O R$ ) with 95\% confidence interval (CI). Results: Thirty-three patients were analysed as cases with 59 controls. Median age was younger in the case group (49 months, IQR 14-72.5) than control group (88 months, IQR 43-116). After adjustment for other covariates, age $<5$ years old $(a O R 5.50,95 \%$ CI $1.95-$ 15.59) and moderate-to-severe grade of disease (aOR 3.50, 95\% CI 1.09-11.09) were significant risk factors of HAM in our study. Conclusion: Risk factors of HAM in children hospitalised in a rural hospital were age $<5$ years old and moderate-tosevere grade of disease.
\end{abstract}

Keywords: Hospital-acquired malnutrition, children, rural hospital

\section{INTRODUCTION}

Children are more vulnerable to malnutrition due to a higher amount of energy required for growth and their limited energy reserve (Gouveia \& Silva, 2017). Hospitalised children have an increased energy requirement to cater for higher metabolic demands and nutrient turnover rates. These conditions place children at risk of malnutrition and subsequent deterioration of their nutritional status after hospital admission, which is known as hospitalacquired malnutrition (HAM) (Quadros et al., 2018).

\footnotetext{
*Corresponding author: Damar Prasetya, M.Sc

Departemen Ilmu Kesehatan Anak, Fakultas Kedokteran, Kesehatan Masyarakat, dan Keperawatan Universitas Gadjah Mada/ Rumah Sakit Umum Pusat Dr. Sardjito, Jalan Kesehatan nomor 1, Yogyakarta 55284.

Email: damarprasetya@live.com; Tel: +6282214957229

doi: https://doi.org/10.31246/mjn-2020-0083
} 
Malnutrition relates to worse clinical outcomes, such as prolonged recovery time and higher requirements of intensive care. Malnutrition also increases complications, nosocomial infections, and mortality rates. Longer length of stay in hospital and more complicated treatments of malnourished patients are also an economic burden (Mazzocchi, 2015).

Nutritional assessment and management are integral parts of a holistic treatment in all hospitalised patients. These interventions should ideally be conducted by a multidisciplinary team consisting of paediatrician, nutritionist, nurses, and other hospital staff. However, daily and comprehensive management to all hospitalised children are sometimes time-consuming and difficult to obtain due to the lack of resources (McCarthy et al., 2019; Mehta et al., 2013; Walls et al., 2012).

The shortage of paediatricians and nutritionists in West Borneo is immense. In the 2018 National Health Report of the Republic of Indonesia, there were only 33 nutritionists and one paediatrician across all health facilities in Sanggau Regency, West Borneo, with its 463,995 inhabitants. Particularly in Parindu Hospital, there is only one visiting paediatrician working twice a week and one certified nutritionist responsible for the entire hospitalised patients. This situation is a common problem in many similar hospitals in the rural areas of West Borneo, making ideal nutritional management challenging (Kemenkes RI, 2018; MOH Republic of Indonesia, 2017).

Identification of risk factors and implementation of nutritional screening tools will help hospital staff put more attention on paediatric patients with a higher probability of having HAM (Joosten \& Hulst, 2011; Spagnuolo et al., 2013). These will be helpful in hospitals with a lack in human resources. Previous studies have been conducted in tertiary hospitals in Indonesia, but studies in rural hospital settings are lacking. Rural hospitals have a different subset of patients, diagnoses, and available resources. This study therefore aims to delineate the risk factors of HAM among hospitalised children in the rural hospital of Parindu, Sanggau Regency, West Borneo, Indonesia.

\section{MATERIALS AND METHODS}

This was a nested case-control study derived from a cohort of a nutritional screening programme conducted in Parindu Hospital, Sanggau Regency, West Borneo Province, Indonesia, from December 2018 to February 2019.

The inclusion criteria for cases were: 1) Patients aged 2 months to 18 years old; 2) Hospitalised $\geq 48$ hours; 3) Had complete daily anthropometry measurement data; 4) A loss of body weight $>2 \%$ compared to initial reference weight (Gouveia \& Silva, 2017). Controls were selected from a similar population that yielded the cases, but without any loss of body weight $>2 \%$ compared to initial reference weight. Exclusion criteria were as follows: 1) Referred to another hospital within two days of hospitalisation; 2) Death within 2 days of hospitalisation.

Anthropometry was performed by a certified nutritionist on patients with minimal or without clothing during their hospital stay, in the morning and after voiding. The measurement of dehydrated patients was performed after dehydration was resolved, which was confirmed by a physician-in-charge. Anthropometry findings were plotted on the World Health Organization (WHO) Growth Standards 2006 to assess nutritional status based on weight-forheight $z$-score $(\mathrm{WHZ}$ ) for children $<5$ years old and body mass index-for-age 
(BMI/age) $z$-score for children $\geq 5$ years old. Chronic malnutrition, based on the WHO criteria, was diagnosed with heightfor-age $z$-score (HAZ) below -2 standard deviation (SD) (Gouveia \& Silva, 2017).

Fever was defined as a rise in body temperature by any measurement of $>37.5{ }^{\circ} \mathrm{C}$ for $\geq 2$ days. Gastrointestinal loss was defined as either diarrhoea or vomiting $>3$ times/day or any increase in stoma quantity for $\geq 2$ days. Classification of disease inflammation severity was based on stress factors derived from the American Academy of Pediatrics (AAP) and the American Dietetic Association (ADA). Grade 1 conditions involved mild stress factors e.g., admission for diagnostic procedures, minor infection not necessarily requiring hospitalisation or other mild episodic illnesses. Grade 2 conditions involved moderate stress factors e.g., severe but not lifethreatening infection, fracture or chronic illness without acute deterioration. Grade 3 conditions involved severe stress factors e.g. AIDS, malignancy, severe sepsis, major surgery, multiple injuries or acute deterioration of chronic disease (Maryani et al., 2016; Sermet-Gaudelus et al., 2000).

All statistical analyses were performed using SPSS 24.0 for Windows. Univariate analysis using chisquare or Fisher's exact test was done between independent and dependent variables. Risk factors were expressed as odds ratio $(O R)$ or adjusted odds ratio $(a O R)$ with $95 \%$ confidence interval $(\mathrm{CI})$. Logistic regression was performed to identify significant risk factors of HAM. To identify all variables known to be important in the multivariate analysis, purposeful selection method was applied by including variables with a significant univariate test and any variables with a $p$-value of $<0.25$ (Bursac et al., 2008). Significance level was considered at $p<0.05$.
Written informed consent was obtained from parents or accompanying guardians during the hospital stay. Ethical approval was obtained from the Medical and Health Research Ethics Committee of Universitas Gadjah Mada under protocol number $\mathrm{KE} / 0354 / 03 / 2019$. All information about the subjects were decoded to make them confidential.

\section{RESULTS}

Thirty-three patients with HAM served as cases with 59 subjects considered as controls. The median age of all subjects was 64.5 months (Interquartile range/IQR 30-108). The median age was younger in the case group (49 months old) compared to the control group (88 months old). Pre-existing acute malnutrition was found in $27.1 \%$ subjects, of which $6(6.5 \%)$ had severe malnutrition and 19 (20.6\%) had moderate malnutrition. Chronic malnutrition was found in $26(28.2 \%)$ patients with a higher proportion in the case group $(36.3 \%)$ than in the control group $(23.7 \%)$.

Most patients were hospitalised due to infectious diseases, of which dengue infection was the most prominent diagnosis, followed by acute gastroenteritis. Five patients $(5.4 \%)$ were hospitalised due to surgical disease. The length of stay in both groups was similar. Only seven patients $(7.6 \%)$ were hospitalised for $>7$ days, with a maximum stay of ten days in three patients. The baseline characteristics of the subjects are depicted in Table 1.

The clinical profile of our study subjects is shown in Table 2. Children aged $<5$ years old had a higher proportion of HAM $(69.7 \%)$ than children who were $\geq 5$ years old $(30.3 \%)$. In univariate analysis, age $<5$ years old, fever $>48$ hours, and moderate-to-severe grade 
Table 1. Baseline characteristics of subjects

\begin{tabular}{|c|c|c|c|c|}
\hline \multirow{2}{*}{ Variables } & \multicolumn{2}{|c|}{ Cases ( $n=33$ ) } & \multicolumn{2}{|c|}{ Controls $(n=59)$} \\
\hline & $n$ & $\%$ & $n$ & $\%$ \\
\hline \multicolumn{5}{|l|}{ Sex } \\
\hline Male & 14 & 42.4 & 24 & 40.7 \\
\hline Female & 19 & 57.6 & 35 & 59.3 \\
\hline \multicolumn{5}{|l|}{ Initial nutritional status } \\
\hline Severely wasted & 3 & 9.1 & 3 & 5.1 \\
\hline Wasted & 7 & 21.2 & 12 & 20.3 \\
\hline Normal & 23 & 69.7 & 43 & 72.9 \\
\hline Overweight & 0 & 0.0 & 1 & 1.7 \\
\hline Obese & 0 & 0.0 & 0 & 0.0 \\
\hline \multicolumn{5}{|l|}{ Initial height } \\
\hline Normal height & 21 & 63.7 & 45 & 76.3 \\
\hline Stunted & 4 & 12.1 & 9 & 15.3 \\
\hline Severely stunted & 8 & 24.2 & 5 & 8.4 \\
\hline Length of stay, median days (range) & \multicolumn{2}{|c|}{$4(2-10)$} & \multicolumn{2}{|c|}{$4(2-10)$} \\
\hline \multicolumn{5}{|l|}{ Diagnosis } \\
\hline Infection & 26 & 78.8 & 44 & 74.6 \\
\hline Surgery & 2 & 6.0 & 3 & 5.1 \\
\hline Others (e.g. epilepsy, asthma, dyspepsia) & 5 & 15.2 & 12 & 20.3 \\
\hline
\end{tabular}

Table 2. Clinical profile of subjects

\begin{tabular}{|c|c|c|c|}
\hline \multirow{2}{*}{ Variable } & \multicolumn{3}{|c|}{ Hospital-acquired malnutrition } \\
\hline & Total, $n=92$ & Cases, $n=33$ & Controls, $n=59$ \\
\hline \multicolumn{4}{|l|}{ Age, $n(\%)$} \\
\hline$<5$ years old & $42(45.6)$ & $23(69.7)$ & $19(32.2)$ \\
\hline$\geq 5$ years old & $50(54.4)$ & $10(30.3)$ & $40(67.8)$ \\
\hline \multicolumn{4}{|c|}{ Acute malnutrition, $n(\%)$} \\
\hline Yes & $24(26.0)$ & $10(30.3)$ & $14(23.7)$ \\
\hline No & $68(74.0)$ & $23(69.7)$ & 45 (76.3) \\
\hline \multicolumn{4}{|c|}{ Chronic malnutrition, $n(\%)$} \\
\hline Yes & $26(28.2)$ & $12(36.4)$ & $14(23.7)$ \\
\hline No & $66(71.8)$ & $21(63.6)$ & 45 (76.3) \\
\hline \multicolumn{4}{|l|}{ Length of stay, $n(\%)$} \\
\hline$>7$ days & 7 (7.6) & $3(9.1)$ & $4(6.8)$ \\
\hline$\leq 7$ days & $85(92.4)$ & 30 (90.9) & $55(93.2)$ \\
\hline \multicolumn{4}{|c|}{ Fever $\geq 48$ hours, $n(\%)$} \\
\hline Yes & $54(58.6)$ & $24(72.7)$ & $30(50.8)$ \\
\hline No & $38(41.4)$ & $9(27.3)$ & $29(49.2)$ \\
\hline \multicolumn{4}{|c|}{ Gastrointestinal loss, $n(\%)$} \\
\hline Yes & $20(21.7)$ & $11(33.3)$ & $9(15.2)$ \\
\hline No & $72(78.3)$ & $22(66.7)$ & $50(84.8)$ \\
\hline \multicolumn{4}{|c|}{ Grade of disease, $n(\%)$} \\
\hline Moderate-Severe & 57 (62.0) & $26(78.8)$ & 31 (52.5) \\
\hline Mild & 35 (38.0) & $7(21.2)$ & $28(47.5)$ \\
\hline
\end{tabular}


Table 3. Multivariate analysis of risk factors for hospital-acquired malnutrition

\begin{tabular}{|c|c|c|c|c|c|c|}
\hline \multirow{2}{*}{ Risk Factor } & \multicolumn{3}{|c|}{ Univariate Analysis } & \multicolumn{3}{|c|}{ Multivariate Analysis } \\
\hline & Crude OR & $95 \% C I$ & $p$-value & Adjusted OR & $95 \% C I$ & p-value \\
\hline \multicolumn{7}{|l|}{ Age } \\
\hline$<5$ years old & 4.82 & $1.93-12.17$ & $<0.01$ & 5.50 & $1.95-15.59$ & $<0.01$ \\
\hline$\geq 5$ years old & 1.00 & & & 1.00 & & \\
\hline \multicolumn{7}{|l|}{ Acute malnutrition } \\
\hline Yes & 1.40 & $0.53-3.63$ & 0.49 & - & - & \\
\hline No & 1.00 & & & & & \\
\hline \multicolumn{7}{|l|}{ Chronic malnutrition } \\
\hline Yes & 1.84 & $0.72-4.65$ & 0.19 & 1.70 & $0.57-5.10$ & 0.34 \\
\hline No & 1.00 & & & & & \\
\hline \multicolumn{7}{|l|}{ Length of stay } \\
\hline$\geq 7$ days & 1.37 & $0.28-6.55$ & $0.69^{+}$ & - & - & \\
\hline$<7$ days & 1.00 & & & & & \\
\hline \multicolumn{7}{|l|}{ Fever $\geq 48$ hours } \\
\hline Yes & 3.35 & $1.26-8.92$ & 0.04 & 1.99 & $0.67-5.95$ & 0.21 \\
\hline No & 1.00 & & & & & \\
\hline \multicolumn{7}{|l|}{ Gastrointestinal loss } \\
\hline Yes & 2.58 & $1.03-6.47$ & 0.04 & 3.19 & $1.00-10.20$ & 0.05 \\
\hline No & 1.00 & & & & & \\
\hline \multicolumn{7}{|l|}{ Grade of disease } \\
\hline Moderate-Severe & 2.78 & $1.01-7.65$ & 0.01 & 3.50 & $1.09-11.19$ & 0.03 \\
\hline Mild & 1.00 & & & & & \\
\hline
\end{tabular}

${ }^{\dagger}$ Fisher's exact test

of disease have a $p$-value $<0.05$. These three variables and chronic malnutrition variables with a $p$-value of $<0.25$ were analysed further in logistic regression to be expressed as $a O R$.

Risk factors are described in $O R$ as depicted in Table 3. After adjustment for other covariates, age $<5$ years old $(a O R$ $5.50,95 \%$ CI 1.95-15.59) and moderateto-severe grade of disease (aOR 3.50, 95\% CI 1.09-11.09) were significant risk factors of HAM in our study, with the age of patient having the most significant odds ratio.

\section{DISCUSSION}

Pre-existing malnutrition was prevalent in our subjects. Twenty-four patients (26\%) had acute malnutrition upon admission. Among patients with HAM, $23(69.7 \%)$ patients had a normal nutritional status upon admission compared to ten (30.3\%) patients with pre-existing acute malnutrition. Several studies found that the incidence of HAM was higher in previously well-nourished children. This might be caused by the higher catabolic process that exceeds the anabolic process in well-nourished children (Rocha, Rocha \& Martins, 2006; Gouveia \& Silva, 2017).

Children with chronic malnutrition have a decreased level of amino acids. A diminished level of amino acid storage will increase gluconeogenesis in the liver and amino acid breakdown in muscles (Nasar et al., 2014; Mac \& Gap, 2017). These conditions will deteriorate the nutritional status of children who are in a state of illness. Although a higher proportion of HAM was found in patients with pre-existing chronic malnutrition, 
the result was not significant in either univariate or multivariate analyses.

Length of hospital stay was associated with weight loss during hospitalisation in several previous studies (Rocha et al., 2006; Joosten \& Hulst, 2011; Shaughnessy \& Kirkland, 2016). However, in our study, the median duration of stay was similar in both groups. This finding might have been caused by the different conditions of patients admitted to our hospital compared to previous studies that were conducted in bigger hospitals that usually have more variety of diagnosis and length of stay.

The age of patients was a significant risk factor in this study. Patients aged $<5$ years old had a 5-fold higher chance of having HAM (OR 5.50, 95\% CI 1.9515.59), as demonstrated by the higher proportion of HAM in children aged $<5$ years old $(69.7 \%)$ than children aged $>5$ years old $(30.3 \%)$. Younger children have higher energy per unit body mass and daily energy requirement, which makes the imbalance between daily requirement and consumption more severe than in older children. Any increase in nutritional demands experienced by hospitalised children will compete with the calorie requirement needed for growth that is higher in younger children (Mazzocchi, 2015). The difference in body composition among age groups also contributes to a higher risk of younger children having malnutrition (Djafarian et al., 2015).

Fever, burns, ascites or fluid loss can alter the balance between calorie consumption and requirement, which contributes to HAM (Mehta et al., 2013; Shaaban, Nassar \& El-Gendy, 2018). In our study, half of the patients with HAM had some kind of gastrointestinal loss although this finding was not statistically significant. Fever increases calorie requirements in children, whereby heat production increases calorie requirement by 13 percent for each degree Celcius (Gouveia \& Silva, 2017). However, similar to a previous study, after adjustment for other covariates, fever for more than 48 hours was not a significant risk factor of HAM (Maryani et al., 2016).

Response to trauma, infection or inflammation in acute or chronic diseases may result in malnutrition through the alteration of metabolism, appetite, absorption or assimilation of nutrients (Mazzocchi, 2015). Any state of disease, whether critical or not, may directly or indirectly influence components of energy expenditure. This will subsequently have a marked effect on the nutritional status of a child. Thus, underestimation or overestimation of energy during illness can result in an energy imbalance that contributes to HAM (Maryani et al., 2016; Mazzocchi, 2015).

The underlying disease of a patient is related to weight loss during hospitalisation. Diseased tissue promotes an acute inflammatory response which results in rapid lean body mass catabolism. A disease also frequently induces anorexia and fever, vomiting or diarrhoea, which worsens the imbalance between requirement and intake (Mehta et al., 2013). The grade of disease was a significant risk factor of HAM in this study (OR 3.50, 95\%CI 1.09-11.19). Children admitted due to moderate-to-severe or grades 2 or 3 disease according to AAP or ADA were associated with body weight loss $>2 \%$ (Maryani et al., 2016; Sermet-gaudelus et al., 2000).

There were several limitations in this study. We did not classify the severity of fever and gastrointestinal loss in this study, whereas theoretically, the severity of fever and loss correlate with the severity of weight loss. The spectrum of diagnosis in our study was also not 
broad although it does reflect our local pattern of hospitalisation in a rural hospital in Indonesia.

HAM is an overlooked problem, especially in rural hospital settings. Daily nutritional observation and intervention for every single patient admitted to the hospital is time-consuming when limited human resources is available. There are several ways to overcome this situation. First, by using simple nutritional screening tools such as STRONG $_{\text {KIDS }}$ (Screening Tool for nutritional status and growth) to determine the risk of malnutrition upon admission to the hospital (Children et al., 2015; Joosten \& Hulst, 2011). Second, with the identification of risk factors, close observation of patients with a high risk of malnutrition can be performed to facilitate early prevention and intervention. Third, training of nurses or hospital staff other than nutritionists to make comprehensive assessments and possible interventions (Girsang \& Sidiartha, 2018; Joosten \& Hulst, 2011; McCarthy et al., 2019). These strategies and options can be considered based on local regulations and the capacity of each health facility.

\section{CONCLUSION}

Risk factors of hospital-acquired malnutrition are age $<5$ years old and moderate-to-severe grade of disease. Identification of these risk factors and the implementation of nutritional screening tools should be performed in rural hospitals to overcome hospital-acquired malnutrition problems in children.

\section{Acknowledgement}

The authors would like to thank Mislaini Matondang, all nurses team and nutritionists of Parindu Hospital, Sanggau, West Borneo, Indonesia. The authors would also like to thank the children, their parents, and the multidisciplinary team that helped in the study process.

\section{Authors' contributions}

DP, principal investigator, performed data analysis and interpretation, conceptualised and designed the study, prepared the draft of the manuscript and reviewed the manuscript; $\mathrm{SH}$, led the data collection; NN, performed data analysis and interpretation, assisted in drafting of the manuscript and reviewed the manuscript.

\section{Conflict of interest}

The authors declared no potential conflicts of interest with respect to the research, authorship and publication of this article. All authors received no specific grants from any funding agency in the public, commercial or non-profit sectors.

\section{References}

Bursac Z, Gauss CH, Williams DK \& Hosmer DW (2008). Purposeful selection of variables in logistic regression. Source Code Biol Med 3:1-8.

Children H, Gholampour Z, Hosseininasab M, Khademi G \& Sezavar M (2015). Assessment of Nutritional Status Based on STRONGkids Tool in Iranian Assessment of Nutritional Status Based on STRONG kids Tool in Iranian Hospitalized Children. Int $J$ Child Health Nutr 4(1):1-5.

Djafarian K, Speakman J, Stewart J \& Jackson D (2015). Body composition and basal metabolic rate in pre-school children: no sex difference. $J$ Nutr Sci Diet 1(2):86-92.

Girsang SN \& Sidiartha IGL (2018). The incidence of in-hospital malnutrition in children at Sanglah Hospital Denpasar And its association with length of stay The incidence of in-hospital malnutrition in children at Sanglah Hospital Denpasar and its association with length of stay. Medicina 48(2):98-102.

Gouveia M \& Silva G (2017). Hospital Malnutrition in Pediatric Patients: A Review. Ann Nutr Disord \& Ther 4(2):1-6. https://doi.org/10.26420/ annnutrdisordther.2017.1042

Joosten KFM \& Hulst JM (2011). Malnutrition in pediatric hospital patients: Current issues. Nutrition 27(2):133-7.

Kemenkes RI (2018). Hasil Utama Riskesdas 2018. In KKR Indonesia (Ed.), Riset Kesehatan Dasar. Kementrian Kesehatan Republik Indonesia.

Mac G \& Gap S (2017). Hospital Malnutrition in Pediatric Patients: A Review. Ann Nutr Disord \& Ther 4(2):1-6.

Maryani E, Prawirohartono EP \& Nugroho S (2016). Predictors of In-Hospital Malnutrition in Children. Sari Pediatri, 18(4):278-84. 
Mazzocchi A (2015). Energy requirements of pediatric patients. Universita Degli Studi Di Milano.

McCarthy A, Delvin E, Marcil V, Belanger V, Marchand V, Boctor D, Rashid M, Noble A, Davidson B, Groleau V, Spahis S, Roy C \& Levy E (2019). Prevalence of malnutrition in pediatric hospitals in developed and intransition countries: The impact of hospital practices. Nutrients 11(236):1-18.

Mehta NM, Corkins MR, Lyman B, Malone A, Goday PS, Carney L, Monczka JL, Plogsted SW \& Schwenk WF (2013). Defining pediatric malnutrition: A paradigm shift toward etiologyrelated definitions. $J$ Parenter Enteral Nutr 37(4):460-81.

MOH Republic of Indonesia. (2017). Health profile of West Borneo Province. In Health profile of West Borneo Province Year of 2017 (Issue 7). Ministry of Health Republic of Indoneisa. From: https://dinkes.kalbarprov.go.id/wp-content/ uploads / 2018/08/PROFIL-KESEHATANPROV-KALBAR-TH-2017.pdf [Retrieved May 29, 2019]

Nasar SS, Susanto J, Lestari ED, Djais J \& Prrawitasari T (2014). Hospital Malnutrition. In D Sjarif, E Lestari, M Mexiatalia \& S Nasar (Eds.), Textbook of Nutrition and Metabolic Diseases (2nd ed., pp. 171-182). Indonesian Pediatric Society.

Quadros DRS, Kamenwa R, Akech S \& Macharia WM (2018). Hospital-acquired malnutrition in children at a tertiary care hospital. South Afr J Clin Nutr 31(1):8-13.
Rocha GA, Rocha EJM \& Martins CV (2006). The effects of hospitalization on the nutritional status of children. J Pediatr, 82(1):70-4.

Sermet-Gaudelus I, Poisson-Salomon AS, Colomb V, Brusset MC, Mosser F, Berrier F \& Ricour C (2000). Simple pediatric nutritional risk score to identify children at risk of malnutrition. $\mathrm{Am}$ $J$ Clin Nutr 72(1):64-70.

Shaaban S, Nassar M, El-Gendy YESB (2018). Nutritional risk screening of hospitalized children aged under three years. East Mediterr Health $J$ 10:1-5.

Shaughnessy EE \& Kirkland LL (2016). Malnutrition in Hospitalized Children : A Responsibility and Opportunity for Pediatric Hospitalists. Hospital Pediatrics 6(1):37-42.

Spagnuolo MI, Liguoro I, Chiatto F, Mambretti D \& Guarino A (2013). Application of a score system to evaluate the risk of malnutrition in a multiple hospital setting. Ital $J$ Pediatr 39(81):1-7.

Walls T, Day A, Moeeni V, Walls T \& Day AS (2012). Assessment of nutritional status and nutritional risk in hospitalized Iranian children Assessment of nutritional status and nutritional risk in hospitalized. Acta Paediatr 101:446-51. 